\title{
A System Mode Selection Approach to Integrated Urban-rural Water Supply System Constructions Based on Risk Management
}

\author{
Yihua Mao ${ }^{1, a^{*}}$, Bing Yang ${ }^{1, b}$ and Fangmin Ren ${ }^{1, c}$ \\ ${ }^{1}$ College of Civil Engineering and Architecture, Zhejiang University, Hangzhou, Zhejiang, China \\ amao yihua@zju.edu.cn, bescapeeyb@zju.edu.cn, ${ }^{c}$ rachel1106@yeah.net
}

Keywords: Urban-rural Integration; Water Supply System; Risk Management; Selection Approach.

\begin{abstract}
With more and more attention paid to water supply problems in rural areas, actions have been taken to address it, and the practices in China have proved that the integrated urban-rural water supply system constructions would be a good choice. Two typical modes of the system construction were reviewed in this paper, and which mode is better is a problem for decision-makers. To solve the problem, an approach based on risk management is established, and the mode with the smaller risk value is regarded as the better one. The approach will contribute to the decision-making of the integrated urban-rural water supply system constructions.
\end{abstract}

\section{Introduction}

The water supply system is one of the most important basic facilities to society for its intimate connections with us. It is unimaginable nowadays if an normal running water supply system is absent, especially for those people living in big cities. With much larger population density than the rural area, the water demand from urban areas is hard to be fulfilled. That is why water supply systems are widely constructed in cities while little attention is paid to water supply problems of small villages, which resulted in the unbalanced distribution of water supply systems. This is especially true in many developing countries, where the urban-rural gap trends to be bigger.

With the rapid economic growth, more and more attention is given to the urban-rural gaps. Of all the problems to be addressed in rural areas, basic facilities constructions are the most urgent, and the water supply system construction is one of them. In many rural areas, the water supply system is small, whose water treatment techniques are backward, the management staff are not well trained, pipelines are timeworn and the distribution of the system are not well planned.

To improve the conditions of water supply in rural areas, a variety of actions have been taken in China. Considering the different characteristics among different districts, two ways are suggested. For those rural areas far from big cities, single water supply systems, who are independent from city water supply systems, shall be constructed. And for those rural areas who are near the cities, the water supply problems can be solved by making full use of the existing water supply systems in the city, which means the city water supply system will meet the water demand from both the urban and rural areas. Systems like this are named integrated urban-rural water supply systems. In practice, different modes have been explored to make integrated urban-rural water supply systems work. For a region taking the integrated urban-rural water supply system with better system mode remains a question. System construction is full of risks, and the less the system risk value is, the better the system mode can be regarded. In the perspective of risk management, this paper will try to establish the selection approach to help decision makers choose the suitable system mode.

\section{Literature Review}

The research and practices about risk management in system engineering have been introduced in water supply systems, and they involve risk identification, risk evaluation and risk treatment. Rak et al (2008) presented the risk elements in water supply systems and tried to prevent from happening by 
establishing the warning system. Mao et al (2015) analyzed the risks that the integrated urban-rural water supply system constructions may encounter and weighted the risks by taking advantage of analytic hierarchy process. The risk identification and evaluation from Mao laid a good foundation for establishing the system mode selection approach, and this paper is the further study of it.

The practice of integrated urban-rural water supply system constructions begins in the very early years of the twenty-first century in China, and related researches can date back it. Researchers found that, among all the practices, the systems had much in common and some typical integrated urban-rural water supply system mode could be concluded. In the process of exploring the success of water supply in Hangzhou, Yang \& Cao (2006) found that two main system modes existed, and they insisted that which mode to choose depended on the conditions of the region. To make the mode selection efficient is the primary goal of this paper.

The research on the mode selection of integrated urban-rural water supply system has not been conducted, but mode selection in other fields can help us a lot. The selection process involves decision-making, and qualitative analysis and quantitative analysis are the two basic methods taken. To address multiple schemes comparison and selection issues, integrated evaluation method based on weighting factor and value engineering are applied in many researches. In this paper, integrated evaluation method based on weighting factor will be taken.

\section{Approach to Selecting the Integrated Urban-rural Water Supply System Mode}

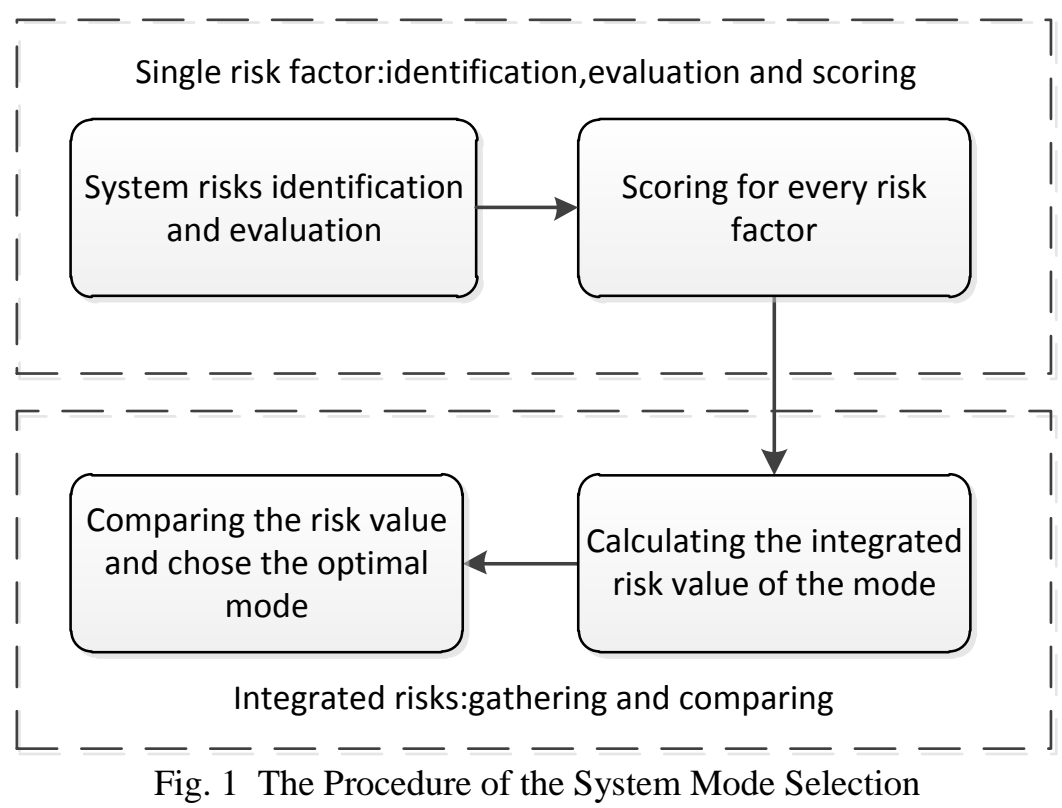

The Framework of the Selection Approach. The primary goal of water supply system is to provide users water with good quality at a reasonable cost, and whether the goal can be achieved depends on the functions of the components in the system. From the perspective of system risk management, the system risk factor may lead to abnormal system operation. The less the system risk value is, the better the system will be. With this idea, when it comes to selecting the construction mode for systems, the optimal system mode should be the one with the least risk value. For different regions, the optimal water supply mode may be different, because the value of risk factors depends on the conditions of the regions, which vary from one another. In other words, to judge whether a mode is optimal for one region, the integrated risk value of different modes in that region must be compared. To measure the integrated risk value, integrated evaluation method based on weighting factor is chosen in this paper. The procedure of mode selection is presented in Fig. 1.

The Risks of the Integrated Urban-rural Water Supply System Constructions. Water supply systems are multiobjective and subject to many constraints. Both the objectives and the constraints can be the risks of the system. In our previous research, the risks of integrated water supply systems had 
been identified by literature review and expert inquiries, and the weight of risk factors had been evaluated by using analytic hierarchy process. The risks and the weight are presented in table 1 .

Table 1 The Results of Risk Evaluation

\begin{tabular}{|l|l|c|l|l|c|}
\hline Number & Risks & Weight & Number & Risks & Weight \\
\hline R1 & $\begin{array}{l}\text { The misjudgment on } \\
\text { geological conditions }\end{array}$ & 0.036 & R9 & $\begin{array}{l}\text { Water contamination } \\
\text { pipelines }\end{array}$ & 0.035 \\
\hline R2 & $\begin{array}{l}\text { The misprediction of water } \\
\text { demand }\end{array}$ & 0.121 & R10 & Equipment failure & 0.024 \\
\hline R3 & Insufficient water resources & 0.072 & R11 & Slow responses in emergencies & 0.035 \\
\hline R4 & Deterioration of raw water & 0.081 & R12 & The overrun of construction cost & 0.163 \\
\hline R5 & $\begin{array}{l}\text { The failure of Water treatment } \\
\text { technology design }\end{array}$ & 0.015 & R13 & High operating cost & 0.080 \\
\hline R6 & Low reliability of water supply & 0.084 & R14 & Deterioration of water sources & 0.040 \\
\hline R7 & Low water pressure & 0.086 & R15 & The insufficient of supply ability & 0.060 \\
\hline R8 & High leak rate & 0.069 & \multicolumn{4}{|c|}{ Sum of weight } & 1.000 \\
\hline
\end{tabular}

The Main Modes of the Integrated Urban-rural Water Supply System Constructions. Water supply systems are composed of water intake structure, water treatment plants, water delivery and distribution facilities and water users, and the modes of the system can describe the relationships between the elements above. The integrated urban-rural water supply system, aiming at supplying water for people located in much larger regional scope and with significant difference in water utilization, is different from the traditional water supply systems in the city. Fortunately, the practices in China have achieved some success, and two main system modes are identified by case studies. One is the extension of city water supply systems, and the other is the integration of urban and rural water supply systems.

The extension of city water supply systems is to extend the pipelines of city water supply systems to rural areas, and the water intake structure and water treatment plants remain as before. The users from rural areas are new entrants of the system and are served equally as the users from the city. This mode suits when the city water supply system has excessive supply capacity and the rural area is not too far away from the city. Without large-scale constructions of new pressure stabilizing equipment, a reasonable distance between the city and the village is the way to help rural users to get satisfied water pressure.

The integration of urban and rural water supply system is to connect the pipelines in the city with pipelines in rural areas, through which the efficiency of water resources in this region will be promoted and the quality of water in rural areas can be improved too. In the long run, this mode is good for the sustainable development of the water supply system. Besides, the water source from rural areas can help the citizens to respond to the emergencies like water pollution. In a word, the integration of urban and rural water supply system can create a win-win situation.

The practices in China indicate that the two modes vary from each other a lot. Some regions succeeded in the adoption of one mode while others failed when the same mode is taken. It proves that to achieve the success of integrated water supply, the system mode must fit with the conditions of the region and minimize the risks of the water supply system.

Modes Selection Approach by Integrated Evaluation Method. To analyze which mode is better for the water supply region, integrated evaluation method based on risk management is taken. The risk value of the mode in the supply region is determined by the risk factors the system facing and the weight and the score of the risk factors. The relationships among them can be described in Equation 1.

$$
\mathrm{RV}=\sum \omega_{i} * \mathrm{rv}_{\mathrm{i}}
$$

Where RV refers to the risk value of the mode in the supply region, $\omega_{i}$ refers to the weight of the ith risk factor and $\mathrm{rv}_{\mathrm{i}}$ refers to the risk value of the ith risk factor. 
Wherever the water supply system locates, the risk factors can be regarded as the same and the weights of the risk factors are fixed, because it is determined by how importance the factor is to the system, as shown in table 1 . The valve of the risk factor is scored from 0 to 8 depending on the severity of the risk factor is. The scores and how severity it indicates are described in Table 2, and the odd score value is given accordingly.

Table 2 Severity Descriptions of Risk Factors

\begin{tabular}{|l|l|}
\hline Scores & Severity of the risk factors \\
\hline 0 & The risk is negligible \\
\hline 2 & The risk has little negative effects \\
\hline 4 & The risk has modest negative effects \\
\hline 6 & The risk has serious negative effects \\
\hline 8 & The risk can lead to system breakdown \\
\hline
\end{tabular}

For the region who will choose from the two modes of integrated urban-rural water supply system constructions, with all the information surveyed, every risk factor can be scored by experienced experts, and then the risk value of the modes can be calculated. The smaller the risk value is, the better the mode will be.

\section{Case Studies}

To test whether the approach established is helpful in modes selection, two regions, Nantong and Jiaxing, both of which have implemented integrated urban-rural water supply system, are chosen to conduct the case studies.

The Results of Modes Selection in the Target Areas. To evaluate the severity of the risk factors in the target areas, a survey is conducted to get information related to the evaluation. Based on the information acquired, twenty-four experts from the target areas are invited to score for the risk factors. For every risk factor, the scores from all the experts are simply arithmetic averaged. And the results are shown in table 3,where M1 refers to the extension of city water supply system, and M2 refers to the integration of urban and rural water supply system.

Table 3 The Results of Modes Selection

\begin{tabular}{|c|c|c|c|c|c|c|c|c|c|c|c|}
\hline \multirow{3}{*}{ Risks } & \multirow{3}{*}{ Weight } & \multicolumn{4}{|c|}{ Scores of risk factors } & \multirow{3}{*}{ Risks } & \multirow{3}{*}{ Weight } & \multicolumn{4}{|c|}{ Scores of risk factors } \\
\hline & & \multicolumn{2}{|c|}{ Jiaxing } & \multicolumn{2}{|c|}{ Nantong } & & & \multicolumn{2}{|c|}{ Jiaxing } & \multicolumn{2}{|c|}{ Nantong } \\
\hline & & M1 & M2 & M1 & M2 & & & M1 & M2 & M1 & M2 \\
\hline $\mathrm{R} 1$ & 0.036 & 2.5 & 2.4 & 3.8 & 3.6 & R9 & 0.035 & 6.4 & 6.0 & 7.2 & 6.6 \\
\hline $\mathrm{R} 2$ & 0.121 & 3.2 & 3.4 & 3.1 & 3.2 & R10 & 0.024 & 3.6 & 3.6 & 5.2 & 5.6 \\
\hline R3 & 0.072 & 7.4 & 6.2 & 4.6 & 3.8 & R11 & 0.035 & 3.6 & 3.8 & 2.2 & 2.1 \\
\hline $\mathrm{R} 4$ & 0.081 & 7.8 & 6.8 & 4.2 & 3.0 & R12 & 0.163 & 3.2 & 3.2 & 4.6 & 4.8 \\
\hline R5 & 0.015 & 6.2 & 6.6 & 6.4 & 6.5 & $\mathrm{R} 13$ & 0.080 & 4.5 & 4.1 & 4.6 & 5.0 \\
\hline R6 & 0.084 & 4.2 & 3.8 & 4.9 & 4.3 & R14 & 0.040 & 7.4 & 7.0 & 2.1 & 1.4 \\
\hline R7 & 0.086 & 3.8 & 2.2 & 3.8 & 3.6 & R15 & 0.060 & 5.4 & 4.6 & 2.4 & 2.1 \\
\hline R8 & 0.069 & 2.4 & 2.8 & 4.4 & 4.8 & & & & & & \\
\hline & & & & & & & & 4.52 & 4.13 & 4.12 & 3.94 \\
\hline
\end{tabular}

Discussion of the Results from Case Studies. From Table 3, it can be concluded that for both areas studied, the integration of urban and rural water supply system will be a better choice. However, it doesn't mean that the extension of city water supply systems will not be a good mode in any circumstances. The two areas do have many similarities in terms of construction conditions, and that is 
why similar results of modes selection occur. Besides, we noticed that the terrible water sources in Jiaxing contributed a lot to its higher risk value compared with that of Nangtong.

\section{Summary}

The integrated urban-rural water supply system construction is a way to solve water supply problems in rural areas. A few system modes can realize it, and which mode to choose is a problem for decision-makers. The paper reviewed the two common modes of integrated urban-rural water supply system constructions and established an approach based on risk management to selecting an appropriate construction mode for areas who intend to take the system. The approach can help to promote the efficiency of the decision-making in modes selection of integrated urban-rural water supply system constructions.

\section{References}

[1] Zhou Y.Z. et al., Risk Evaluation and Safety Management in Urban Water Supply Systems, Water \& Wastewater Engineering, 2013,39(12):13-16.

[2] Mao Y.H, Yang B.\&Li H.Y., Risk Identification and Evaluation for Decision-making In Integrated Urban-rural Water Supply System Constructions, Energy, Environmental and green Building Materials, 2015.

[3] Yang J.J.\& Cao J., Study on Water Supply and Sewer System Planning of Urban-rural Integration, Journal of Zhejiang University, 2006, 33(1):115-120.

[4] Rak J, Pietrucha K., Some Factors of Crisis Management in Water Supply System, Environment Protection Engineering,2008,34(2): 57.

[5] Chung G., Lansey K.\&Bayraksan, G. Reliable WaterSupply System Design under Uncertainty, Environmental Modelling and Software, 2009,24(4):449-462.

[6] Raman, H.; Mohan, S.\&Baskaran, M. Decision Support System for Water Supply Management, Proceedings of the Symposium on Engineering Hydrology, 1993: 1060-1065.

[7] Simao, Ana; Coutinho-Rodrigues, Joao\&Current, John R. Minimizing network disruption for planned and emergency repairs of water supply systems, Journal of Infrastructure Systems, 2004,10(4):176-180.

[8] Wibowo,A.\&Mohamed,S.,Risk Criticality and Allocation in Privatised Water Supply Projects in Indonesia, International Journal of Project Management,2010,28(5): 504-513.

[9] $\mathrm{Hu}$ Z.H.,Economic Analysis of Integrated Water Supply System and its Mechanism Innovation, Journal of Wenzhou University,2005,18(1):28-35.

[10]Lu R.Q. Niu Z.G. \& Zhang H.W., Research of Risk Assessment of Urban Water Supply System, Water \& Wastewater Engineering,2010,36:4-8. 